\title{
Mass transport analysis for tritium removal in FHRs
}

Xiaodong Sun, Xiao Wu, Shanbin Shi, Sheng Zhang, David Arcilesi, Richard Christensen, Piyush Sabharwall

July 2018

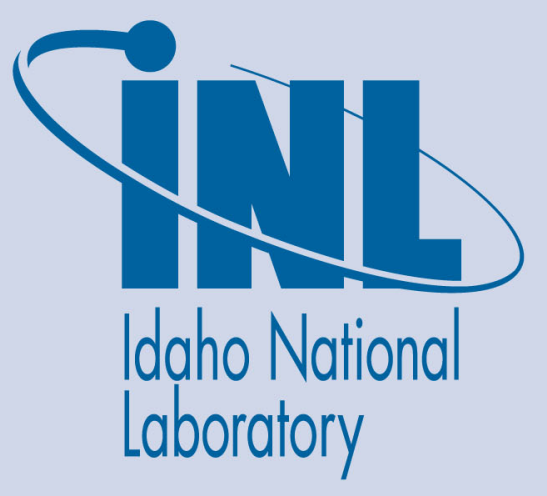

The INL is a U.S. Department of Energy National Laboratory operated by Battelle Energy Alliance 


\title{
Mass transport analysis for tritium removal in FHRs
}

\author{
Xiaodong Sun, Xiao Wu, Shanbin Shi, Sheng Zhang, David Arcilesi, Richard \\ Christensen, Piyush Sabharwall
}

July 2018

Idaho National Laboratory Idaho Falls, Idaho 83415

http://www.inl.gov

\author{
Prepared for the \\ U.S. Department of Energy \\ , Office of Nuclear Energy \\ Under DOE Idaho Operations Office \\ Contract DE-AC07-05ID14517, DE-AC07-05ID14517
}




\title{
Mass Transport Analysis for Tritium Removal in FHRs
}

\author{
Xiao $\mathrm{Wu}^{\mathrm{a}, \mathrm{b}}$, Shanbin Shi ${ }^{\mathrm{a}, \mathrm{b}}$, Sheng Zhang ${ }^{\mathrm{a}, \mathrm{b}}$, David Arcilesi ${ }^{\mathrm{b}, \mathrm{c}}$, Richard Christensen ${ }^{\mathrm{b}, \mathrm{c}}$, \\ Piyush Sabharwall ${ }^{\mathrm{d}}$, Xiaodong Sun ${ }^{\mathrm{a}, \mathrm{b}}$ \\ ${ }^{a}$ Department of Nuclear Engineering and Radiological Sciences, University of Michigan \\ 2355 Bonisteel Blvd, Ann Arbor, MI 48109 \\ ${ }^{b}$ Nuclear Engineering Program, Department of Mechanical and Aerospace Engineering, The \\ Ohio State University \\ $201 \mathrm{~W} 19^{\text {th }}$ Ave, Columbus, OH 43210 \\ ${ }^{c}$ Nuclear Engineering, University of Idaho \\ 1776 Science Center Drive, Idaho Falls, ID 83402 \\ ${ }^{d}$ Idaho National Laboratory \\ 2525 Fremont Ave, Idaho Falls, ID 83402
}

\begin{abstract}
Tritium control and mitigation is one of the most significant issues in Fluoride Salt-cooled High-temperature Reactors (FHRs). To address this issue, a cross-flow tritium removal facility has been proposed to remove molecular tritium, $\mathrm{T}_{2}$, from the primary coolant. To model the performance of the design, a method is developed based on the logarithmic mean difference of the square root of the tritium partial pressures on the upstream side and the purging gas side. A computer code has been developed based on this global analysis method to study the effectiveness of tritium removal in such a cross-flow tritium removal facility. The code is benchmarked against experimental data from a hydrogen separation experiment in the literature and compared with results from a code based on traditional Finite Volume Method. Evaluation of the cross-flow
\end{abstract}


tritium removal facility designed for FHR systems has also been performed. The results show how the key factors, i.e., fluid flow rates and tritium inlet concentration affect the performance of the facility.

\section{Keywords}

Fluoride Salt-cooled High-temperature Reactor, tritium removal, mass transport

\section{Highlights}

- A Logarithmic Mean Square root of Partial Pressure Difference (LMSPD) method is developed for a cross-flow tritium removal facility designed for FHRs and a code based on the method is benchmarked against a hydrogen permeation experiment

- An overall mass transfer code based on the LMSPD method is applied to the calculation of a cross-flow tritium removal facility for the first time

- Parametric study of the cross-flow tritium removal facility is performed and the results confirmed that flow rates and inlet $T_{2}$ concentration are the key factors affecting the tritium removal facility performance

*Corresponding author: Xiaodong Sun

Department of Nuclear Engineering and Radiological Sciences

University of Michigan

2355 Bonisteel Blvd.

Ann Arbor, MI 48109-2104

Tel: +1 7346159749

Fax: +1 7347634540

Email: xdsun@umich.edu 


\section{INTRODUCTION}

Fluoride Salt-cooled High-temperature Reactor (FHR) is categorized as a class of Generation IV nuclear fission reactors (Locatelli et al., 2013). FHR uses eutectic salt mixtures as coolants and is, in a general sense, a type of molten salt reactors (Olson et al., 2009). Currently, FLiBe, (66.7 mol\% $\mathrm{LiF}-33.3 \mathrm{~mol}_{\mathrm{o}} \mathrm{BeF}_{2}$ ), is generally considered as the FHR primary coolant. In addition, two salts are considered as potential coolants in the intermediate loop: FLiNaK (a mixture of LiF, $\mathrm{NaF}$ and $\mathrm{KF}$ ) and $\mathrm{KF}-\mathrm{ZrF}_{4}$.

While FHRs possess attractive features, such as enhanced safety with passive safety systems and high power generation efficiency, they face a potentially significant issue, i.e., tritium generation and management (Forsberg et al., 2017; Qin et al., 2018). Tritium is primarily generated in the reactor core from the neutron activation of the primary coolant, FLiBe. The coolant salt is purified and enriched with ${ }^{7} \mathrm{Li}$ to $99.995 \mathrm{wt} \%$. However, due to the large amount of salt needed in the primary loop and the large reaction cross section of ${ }^{6} \mathrm{Li}$ with neutrons, the amount of tritium generated from ${ }^{6} \mathrm{Li}$-neutron reaction is not negligible. Additionally, ${ }^{9} \mathrm{Be}$ also reacts with neutrons to produce ${ }^{6} \mathrm{Li}$. The main reactions of tritium production and their corresponding cross sections are listed in Eqs. (1) - (3):

$$
\begin{gathered}
{ }_{3}^{6} \mathrm{Li}+\mathrm{n} \rightarrow{ }_{2}^{4} \mathrm{He}+{ }_{1}^{3} \mathrm{H}+4.8 \mathrm{MeV} ; \sigma_{\text {th }}=940 \mathrm{~b} \\
{ }_{3}^{7} \mathrm{Li}+\mathrm{n} \rightarrow{ }_{2}^{4} \mathrm{He}+{ }_{1}^{3} \mathrm{H}+\mathrm{n} ; \sigma_{\text {avg }}=20 \mathrm{mb} \\
{ }_{4}^{9} \mathrm{Be}+\mathrm{n} \rightarrow{ }_{2}^{4} \mathrm{He}+{ }_{3}^{6} \mathrm{Li} ; \sigma_{\text {avg }}=36 \mathrm{mb} .
\end{gathered}
$$

The generation rate of tritium in the primary coolant is about $1 \mathrm{Ci} / \mathrm{MW}$ th-day, which is substantially higher than the $0.015 \mathrm{Ci} / \mathrm{MWth}$-day of an average LWR (Wu et al., 2016). Tritium generation in CANDU reactors is about $1.75 \mathrm{Ci} / \mathrm{MWth}$-day (Stempien, 2015) and is comparable 
to that in FHRs. However, the most significant difference between the tritium generated in CANDU reactors and in FHRs is its existence form. In CANDU reactor, the main form of the tritium is tritiated water, either $\mathrm{HTO}$ or $\mathrm{T}_{2} \mathrm{O}$. In FHRs, with effective redox control to reduce the salt corrosion to the primary loop structures, the majority of the tritium in the primary coolant exists in the form of tritium bimolecular gas, $\mathrm{T}_{2}$ (Fukada and Mitsuishi, 1988a). Similar to $\mathrm{H}_{2}, \mathrm{~T}_{2}$ is highly permeable through metal surfaces, especially under the FHR high operating temperatures (Watson, 1972).

In addition, tritium is a weak beta emitter and will cause acute or chronic health issues if inhaled or ingested. The gaseous tritium, $\mathrm{T}_{2}$, tends to convert to tritiated water (HTO) after entering the environment (Qin et al., 2017). The hazard of HTO is 25,000 times of that of $\mathrm{T}_{2}$. As a potential health hazard, tritium mitigation and control in FHRs is essential in order to avoid exceeding the tritium release limits from the reactor system to the surrounding environment (Forsberg et al., 2017). Tritium needs to be prevented from releasing into the surrounding environment, but it cannot be left to accumulate in the primary loop either. Therefore, it is necessary to adopt a mechanism to extract and collect tritium from the primary loop. This situation can be generalized as a gas separation from liquid under high temperature and atmospheric pressure conditions. A number of strategies have been proposed for this purpose. Studies in fusion systems have shown that a permeation window is one of the most effective methods for hydrogen extraction from a coolant system (Watson, 1972; Fukada and Mitsuishi, 1988b). Among the permeation-windowtype designs for tritium removal, a tritium control system featuring a cross-flow tritium removal facility has been proposed (Wu et al., 2016). To evaluate the design of a cross-flow tritium removal facility applied in FHRs, it is necessary to analyze the effectiveness of the designed facility. To 
support the analysis, a literature survey of tritium transport and, more generally, hydrogen isotope transport has been performed.

Permeation of hydrogen isotopes through metals has been extensively studied (Fisher, 1999). It is of interest not only in fusion reactors, but also in fields of hydrogen separation and hydrogen storage for clean energy research. Their main focuses have been on experimental measurements and theoretical model development. Gorman and Nardella (1962) experimentally measured the permeation constant of $\mathrm{H}_{2}$ through various metal samples over a temperature range of $350-950^{\circ} \mathrm{C}$. Steward (1983) reviewed experiments of hydrogen isotopes permeating through metals and nonmetal materials. Correlations for the permeability of hydrogen isotopes in different materials were developed from the experimental data. Deveau et al. (2013) proposed a micro-kinetic model for hydrogen permeation in dense metal membranes based on a detailed investigation of each step of the permeation process. Andrew and Haasz (1992) investigated the effects of surface conditions for hydrogen permeation through different metals, and proposed a model that takes into consideration different flux saturation mechanisms (University of Toronto, 1991).

Apart from experiments, studies of hydrogen isotopes permeating through metals focus on the development of correlations as well as computer codes. Segmentation mass transfer calculation methods divide the geometry into meshes and impose local mass balance in each cell. Fukada and Mitsuishi (1988a) developed a computer code for a tritium permeation window in fusion reactors. The code was applied to tritium transport in laminar flow fluids between two parallel plates across the walls. The calculation results showed that both resistances in the wall and fluids need to be taken into consideration. In another study (Fukada and Mitsuishi., 1988b), they proposed a model to calculate tritium transport through a tube-type metal permeation window. In this model, an overall Sherwood number was defined for calculation of the overall mass transfer coefficient as: 


$$
S h_{o}^{b}=\frac{1}{\left(\frac{1}{S h_{m}}+\frac{G}{2 W_{1}}\right)^{b}+\left(\frac{G}{2}\right)^{b}\left\{\left[\frac{1-C_{m}^{1-n}}{1-n} \ln \left(\frac{1}{C_{m}}\right)\right]^{a}+\left[\frac{1-C_{m}^{1-i \cdot n}}{W_{2}(1-i \cdot n)} \ln \left(\frac{1}{C_{m}}\right)\right]^{a}\right\}^{\frac{b}{a}}},
$$

where, $i$ is a boundary condition index; $a$ and $b$ are parameters depending on $i$; $G$ and $W$ are dimensionless permeation parameters; and $C$ is the dimensionless concentration of hydrogen isotopes.

Wang et al. developed a model to evaluate hydrogen separation efficiency in a hollow nickel fiber membrane system (Wang et al., 2017). The model combines Sievert's law with the ideal gas law, and local mass balance was ensured inside each divided segment. Calculation results were compared to their experimental data and close agreement was obtained. For applications in FHR systems, TRIDENT code (Stempien, 2015) was developed for system-level tritium transport analysis. It incorporates tritium generation, redox control, tritium removal and permeation in the primary loop altogether. This code also utilizes the segmentation method for tritium permeation sections.

Although the segmentation mass transfer calculation method works well for co-current and counter-current flow configurations, it has difficulties when applied to cross-flow configurations. For mass transfer calculation of cross-flow facilities and more generalized applications, a global method is needed. This study developed an overall logarithmic mean square root partial pressure difference (LMSPD) method for mass transfer calculations of bimolecular gases permeating through metal walls. The method utilizes an overall mass transfer coefficient and has essentially no restriction of flow configuration on either side of the permeation wall. A computer code has been written based on the LMSPD method. The cross-flow tritium removal facility designed for tritium control and mitigation in FHRs is evaluated using the LMSPD code. 


\section{CROSS-FLOW TRITIUM REMOVAL FACILITY FOR FHR SYSTEMS}

A cross-flow tritium removal facility designed for FHR systems is schematically shown in Figure 1. In this drawing, only a quarter of the entire tube bank is presented. As can be seen, molten salt flows through the tube bank with sweep gas flowing inside the tubes. The permeated tritium through tube walls will be carried away by the sweep gas, which can be argon or helium. The cross-flow configuration increases the turbulence in the molten salt, leading to a higher mass transfer coefficient. The tube bank is arranged in a staggered manner to ensure the main stream of the molten salt flow is in direct contact with the tube walls.

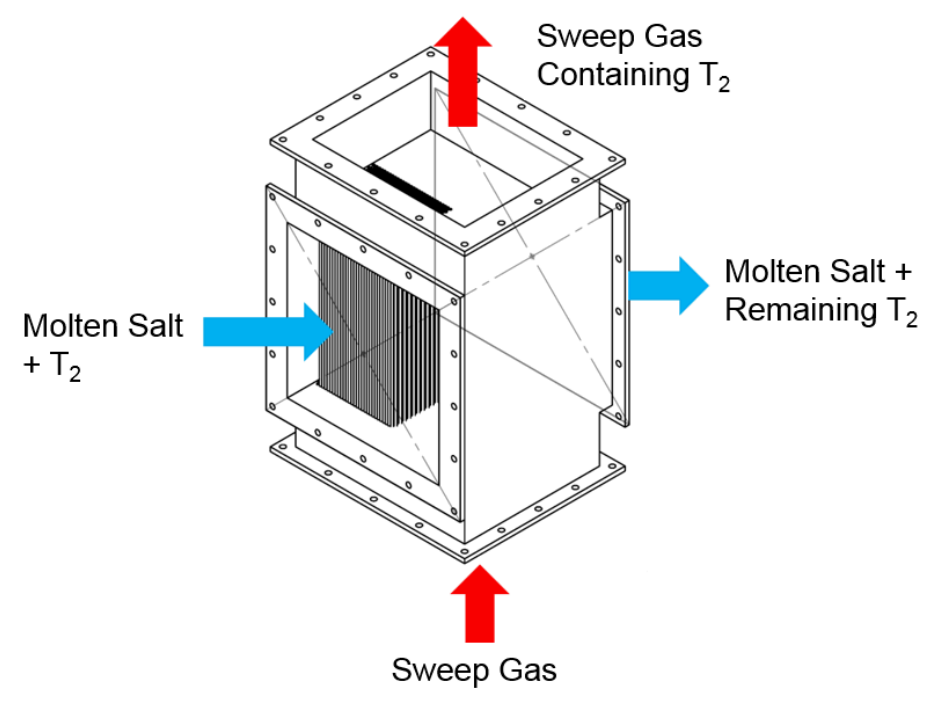

Figure 1 Cross-flow tritium removal facility designed for FHRs

In FHRs, the required tritium removal rate could vary with the reactor power levels. To meet different tritium removal rate requirements, the facility can have a modular design feature. 
Modules can be connected to a main pipe, and the branch flow into each separate facility can be controlled via valves.

To determine the optimal geometry and dimensions of a cross-flow tritium removal facility for a certain application, a parametric study has been performed. The preconceptual design of the Advanced High Temperature Reactor (AHTR) is used as the reference reactor to obtain the operation conditions (Ingersoll, 2004). AHTR is one of the prototypic designs of FHRs. The benefits of optimizing the cross-flow tritium removal facility include a small facility volume and a low pressure drop on the molten salt side. Different combinations of the facility size, molten salt flow rate and purging gas flow rate have been simulated using COMSOL Multiphysics and MATLAB codes. The results are compared to determine the optimized dimension sets (Wu, 2016). The two sets of the optimized dimensions selected are listed in Table 1.

Table 1 Dimensions of the tube bank

\begin{tabular}{|l|c|c|c|}
\hline & Unit & Dimension Set A & Dimension Set B \\
\hline Tube outside diameter (OD) & $\mathrm{mm}$ & 26.67 & 33.40 \\
\hline Tube inside diameter (ID) & $\mathrm{mm}$ & 20.93 & 26.64 \\
\hline Tube wall thickness & $\mathrm{mm}$ & 2.87 & 3.38 \\
\hline Tube bank pitch & $\mathrm{mm}$ & 33.27 & 41.66 \\
\hline Ratio of pitch/OD & - & 1.25 & 1.25 \\
\hline Molten salt inlet frontal area & $\mathrm{mm} \times \mathrm{mm}$ & \multicolumn{2}{|c|}{$457.2 \times 457.2$} \\
\hline
\end{tabular}

\section{TRITIUM MASS TRANSPORT ANALYSIS}

\subsection{Tritium Removal Process in FHRs}

In general, mass transport can be analyzed by analogy to heat transfer. In heat transfer, the driving force is the temperature difference between two objects. Similarly, in mass transport, the 
driving force is the chemical potential. While the chemical potential is difficult to measure or quantify, the driving force of mass transport can also be expressed in the term of partial pressure (Sinha and De, 2012). With the partial pressure in the mass transfer corresponding to the temperature in the heat transfer, the correspondence of the mass transfer parameters to the heat transfer parameters are summarized in Table 2.

In an FHR with a cross-flow tritium removal facility, tritium generated in the primary coolant initially diffuses through the primary coolant and reaches the inner surface of the tube wall, then permeates through the tube metal, and finally is carried away by the sweep gas. In the tritium removal facility, the primary coolant flows on the shell side while the sweep gas flows on the tube side. During the removal process from the primary coolant, tritium encounters both non-metal solvents and metal solvents.

For non-metal solvents, the concentration of tritium is related to its partial pressure via Henry's constant or Sievert's constant, depending on the material where tritium dissolves. Henry's law applies to non-metal solvents, such as the primary and secondary coolants. The relationship between $T_{2}$ concentration and its partial pressure is expressed as:

$$
c=H p,
$$


Table 2 Parameters of mass transfer and heat transfer

\begin{tabular}{|c|c|c|c|c|c|c|c|}
\hline \multicolumn{4}{|c|}{ Mass Transfer } & \multicolumn{4}{|c|}{ Heat Transfer } \\
\hline Parameter & Symbol & Unit & Expression & Parameter & Symbol & Unit & Expression \\
\hline Partial pressure & $p$ & $\mathrm{~Pa}$ & - & Temperature & $T$ & $\mathrm{~K}$ & - \\
\hline Mass diffusivity & $D$ & $\mathrm{~m}^{2} / \mathrm{s}$ & - & Thermal diffusivity & $\alpha$ & $\mathrm{m}^{2} / \mathrm{s}$ & $\alpha=\frac{k}{\rho c_{p}}$ \\
\hline Henry's constant & $H$ & $\mathrm{~mol} / \mathrm{m}^{3}-\mathrm{Pa}$ & - & \multirow{2}{*}{ Heat capacity } & \multirow{2}{*}{$c_{p}$} & \multirow{2}{*}{$\mathrm{J} / \mathrm{kg}-\mathrm{K}$} & \multirow[b]{2}{*}{-} \\
\hline Sievert's constant & $K$ & $\mathrm{~mol} / \mathrm{m}^{3}-\mathrm{Pa}^{0.5}$ & - & & & & \\
\hline Sherwood number & Sh & - & $\mathrm{Sh}=\frac{h l}{D}$ & Nusselt number & $\mathrm{Nu}$ & - & $\mathrm{Nu}=\frac{h_{t} l}{k}$ \\
\hline Schmidt number & Sc & - & $\mathrm{Sc}=\frac{\mu}{\rho D_{\mathrm{AB}}}$ & Prandtl number & $\operatorname{Pr}$ & - & $\operatorname{Pr}=\frac{c_{p} \mu}{k}=\frac{v}{\alpha}$ \\
\hline Peclet number & $\mathrm{Pe}$ & - & $\mathrm{Pe}=\mathrm{ReSc}$ & Peclet number & $\mathrm{Pe}$ & - & $\mathrm{Pe}=\mathrm{Re} \operatorname{Pr}$ \\
\hline Grashof number & $\mathrm{Gr}$ & - & $\begin{aligned} \mathrm{Gr} & =g \beta^{*} l^{3} \Delta c\left(\frac{\rho}{\mu}\right)^{2} \\
\beta^{*} & =-\frac{1}{\rho}\left(\frac{\partial \rho}{\partial c}\right)_{T, p}\end{aligned}$ & Grashof number & Gr & - & $\mathrm{Gr}=g \beta l^{3} \Delta T\left(\frac{\rho}{\mu}\right)^{2}$ \\
\hline Stanton number & $\mathrm{St}$ & - & $\mathrm{St}=\frac{\mathrm{Sh}}{\mathrm{ReSc}}=\frac{\mathrm{Sh}}{\mathrm{Pe}}$ & Stanton number & St & - & $\mathrm{St}=\frac{\mathrm{Nu}}{\mathrm{RePr}}=\frac{\mathrm{Sh}}{\mathrm{Pe}}$ \\
\hline
\end{tabular}


where, $c, p$ and $H$ are the concentration of tritium, partial pressure of tritium gas, and the Henry's constant of tritium in a solvent, respectively.

For metal solvents, such as the metal tube wall, the permeation process of $T_{2}$ can be separated into the following steps (Gorman and Nardella, 1962):

1. Gas diffusion from main stream of the primary fluid to the inner surface of the tube wall. In this step, both convective and diffusive mass transport are involved.

2. Surface absorption into the inner surface of the metal tube wall. A $T_{2}$ molecule will break into two tritium atoms at the interface of molten salt flow and metal tube wall.

3. Permeate through the tube wall. Tritium diffuses inside the metal tube wall in the form of atoms. The chemical potential gradient inside the wall is the driving force of tritium transport in the wall.

4. Surface adsorption from the outer surface of the metal tube wall. Two tritium atoms will recombine into a $T_{2}$ molecule at the outer tube wall surface and then the molecule will transport into the secondary coolant.

5. Gas diffusion from the outer surface of the tube wall to the main stream of the secondary fluid. This step is opposite to the first step.

Among these steps, Step 3 has the dominant mass transfer resistance and affects the tritium permeation rate in metal solvents. Sievert's law applies to bimolecular gases dissolving in metals. Experiments have proved that hydrogen diffusion in a variety of metallic materials, including iron base alloys (Nelson and Stein, 1973), nickel (Wang et al., 2016), palladium-silver alloys (Ackerman and Koskinas, 1972), etc., is in consistence with Sievert's law. Different from Eq. (5), the $T_{2}$ concentration in metals is proportional to the square root of its partial pressure by the Sievert's constant $K$ as: 


$$
c=K \sqrt{p}
$$

\subsection{Interphase Mass Transfer and Overall Mass Transport Coefficient}

To be applicable to cross-flow mass transfer, a global calculation method is necessary. Tritium transport through a metal wall from the primary coolant into the secondary coolant is a typical case of interphase mass transfer. One assumption adopted in this study is that all materials involved are homogenous in terms of physical and chemical properties. A widely-accepted theory is the twofilm theory, which is also known as the two-resistance concept (Treybal, 1980). A schematic of the two-film theory is shown in Figure 2. The concentration of the solute on both sides of an interface depends on the chemical potentials of the solute in both phases. Partial pressure of the solute is continuous across the interface. Concentration in each domain is related to the corresponding partial pressure via either Eq. (5) or (6), depending on the nature of the solvent, i.e., metal or non-metal. Therefore, the concentration of the solute could have a discontinuous jump at the interface.

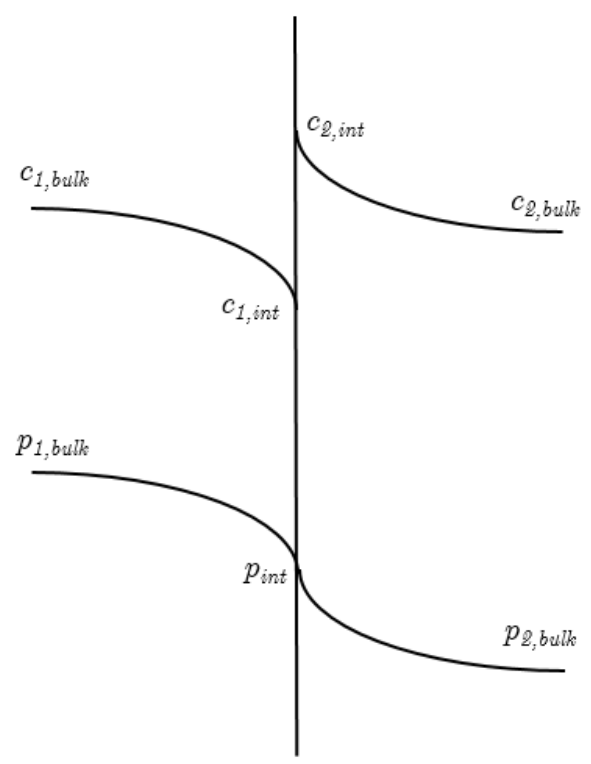

Figure 2 Two-film theory for interphase mass transfer 
The mass transfer coefficients in each domain, $k_{1}$ and $k_{2}$, can be calculated using Fick's law for diffusion and the Sherwood number for convection. In the case of diffusion only, the mass transfer coefficient $k$ is related to diffusivity, $D$, and the transport distance, $d$, as

$$
k=\frac{D}{d} .
$$

The convective mass transfer coefficient can be calculated from the Sherwood number as

$$
k=\frac{\operatorname{Sh} D}{l} .
$$

In this study, correlations for the Nusselt number are adapted for Sherwood number calculations, using the analogous parameters shown in Table 2. The overall mass transfer coefficient $h_{\circ}$ is calculated from

$$
J=h_{o}\left(c_{1, b u l k}-c_{2, b u l k}^{*}\right)
$$

where $J$ is the mass flux, $c_{1, b u l k}$ is the solute concentration in the bulk of material 1 and $c_{2, b u l k}^{*}$ is the corresponding concentration of the solute in material 1 at equilibrium, and is related to $c_{2, b u l k}$ by

$$
c_{2, \text { bulk }}^{*}=m_{\text {convert }} c_{2, \text { bulk }},
$$

where $m_{\text {convert }}$ is a conversion factor at equilibrium and $c_{2, b u l k}$ is the solute concentration in the bulk of material 2.

\subsection{Logarithmic Mean Square root of Partial Pressure Difference (LMSPD) Code for Mass Transport Calculation}

For the tritium transport in FHRs, both metal and non-metal materials are involved. The dependence of the tritium concentration on its partial pressure varies with the transport process. 
Therefore, Eq. (9) cannot be directly applied and modifications need to be made. In the tritium separation process, the mass transfer rate in each material is the same because of the mass balance at steady state. Because of the geometry of the metal tubes, the mass transfer area of each domain is different. For the convenience of permeation flux comparison, an average mass transfer area is defined as

$$
A_{\text {avg }}=\pi L \frac{d_{o}-d_{i}}{\ln d_{1 o}-\ln d_{1 i}}
$$

where $L$ is the tube length, and $d_{o}$ and $d_{i}$ are tube outer and inner diameters, respectively. Based on the continuity of the tritium permeation flux $J$ as well as the overall mass balance, iterations are required for the tritium transport calculation. Detailed calculation and an iteration scheme are described as follows.

The diffusion of $T_{2}$ from the primary coolant main stream to the inner surface of the tube wall can be written as

$$
J=h_{1} \frac{A_{1}}{A_{\text {avg }}}\left(c_{1 b}-c_{1 w}\right)
$$

where $A_{l}$ is the mass transfer area; $c_{l b}$ and $c_{t w}$ are the $\mathrm{T}_{2}$ concentrations in the main stream and at the tube wall surface. By utilizing Eq. (5), Eq. (12) becomes

$$
\begin{aligned}
J & =h_{1} \frac{A_{1}}{A_{\text {avg }}} H_{1}\left(p_{1 b}-p_{1 w}\right) \\
& =h_{1} \frac{A_{1}}{A_{\text {avg }}} H_{1}\left(\sqrt{p_{1 b}}+\sqrt{p_{1 w}}\right)\left(\sqrt{p_{1 b}}-\sqrt{p_{1 w}}\right)=h_{1 p} \frac{A_{1}}{A_{\text {avg }}}\left(\sqrt{p_{1 b}}-\sqrt{p_{1 w}}\right),
\end{aligned}
$$

where $h_{1 p}=h_{1} H_{1}\left(\sqrt{p_{1 b}}+\sqrt{p_{1 w}}\right)$. In the tube wall, the tritium mass flux is 


$$
J=D_{w} \frac{2 \pi L}{A_{\text {avg }}\left(\ln d_{1 o}-\ln d_{1 i}\right)}\left(c_{1 w}-c_{2 w}\right)=D_{w} \frac{2 \pi L}{A_{\text {avg }}\left(\ln d_{1 o}-\ln d_{1 i}\right)} K_{w}\left(\sqrt{p_{1 w}}-\sqrt{p_{2 w}}\right) .
$$

In the secondary coolant, the tritium mass flux is calculated as:

$$
\begin{aligned}
J=h_{2} \frac{A_{2}}{A_{\text {avg }}}\left(c_{2 w}-c_{2 b}\right) & =h_{2} \frac{A_{2}}{A_{\text {avg }}} H_{2}\left(p_{2 w}-p_{2 b}\right) \\
& =h_{2} \frac{A_{2}}{A_{\text {avg }}} H_{2}\left(\sqrt{p_{2 w}}+\sqrt{p_{2 b}}\right)\left(\sqrt{p_{2 w}}-\sqrt{p_{2 b}}\right) \\
& =h_{2 p} \frac{A_{2}}{A_{\text {avg }}}\left(\sqrt{p_{2 w}}-\sqrt{p_{2 b}}\right),
\end{aligned}
$$

where $h_{2 p}=h_{2} H_{2}\left(\sqrt{p_{2 b}}+\sqrt{p_{2 w}}\right)$.

The overall mass transfer equation has the form of

$$
J=h_{o}\left(\sqrt{p_{1 b}}-\sqrt{p_{2 b}}\right)
$$

Combining Eqs. (12) - (16), the overall mass transfer coefficient can be given as:

$$
h_{o}=\frac{1}{\frac{1}{h_{1 p} d_{1 i}}+\frac{\ln d_{1 o}-\ln d_{1 i}}{2 P_{w}}+\frac{1}{h_{2 p} d_{1 o}}} \frac{1}{d_{1 i}} .
$$

The difference of the square roots of the partial pressures in Eq. (16) may be estimated by the logarithmic mean difference of partial pressures in the main streams of the two fluids as:

$$
\sqrt{p_{1 b}}-\sqrt{p_{2 b}}=L M P D=\frac{\left(\sqrt{p_{1 i}}-\sqrt{p_{2 o}}\right)-\left(\sqrt{p_{1 o}}-\sqrt{p_{2 i}}\right)}{\ln \left(\sqrt{p_{1 i}}-\sqrt{p_{2 o}}\right)-\ln \left(\sqrt{p_{1 o}}-\sqrt{p_{2 i}}\right)} .
$$

The mass transfer coefficients in the fluids can be calculated using Sherwood number:

$$
\mathrm{Sh}=\frac{h_{i} d_{h i}}{D_{i}}, i=1 \text { or } 2 .
$$


The Sherwood number itself can be calculated using correlations developed for heat transfer calculations, but with the Nu and Pr replaced by Sh and Sc, respectively (Ranz, 1952), as:

$$
\mathrm{Sh}=\left\{\begin{array}{l}
0.4 \mathrm{Re}^{0.6} \mathrm{Sc}^{0.36} \text { for } 1000 \leq \mathrm{Re} \leq 20000 \\
0.022 \mathrm{Re}^{0.84} \mathrm{Sc}^{0.36} \text { for } \mathrm{Re}>20000 \\
3.41 \text { for } \operatorname{Re}<1000
\end{array}\right.
$$

Figure 4 demonstrates the iteration process to calculate the tritium mass transport rate. To start, a value for the permeation flux $J$ is assumed. With the inlet tritium partial pressures on both sides known, by mass conservation, the partial pressures at the outlets on both sides can be calculated. The LMSPD value can be obtained from the inlet and outlet tritium partial pressures obtained from the previous step. A new permeation flux $J_{n e w}$ can be calculated using the overall mass transport coefficient $h_{0}$. The two values of the permeation flux can be compared. If the absolute difference between these two values ( $J$ and $J_{n a c}$ ) is less than the set error limit $\varepsilon$, the calculation is considered converged and $J_{n e w}$ is the average permeation flux. Otherwise, let $J$ have the value of $J_{n c u}$ and repeat the iteration.

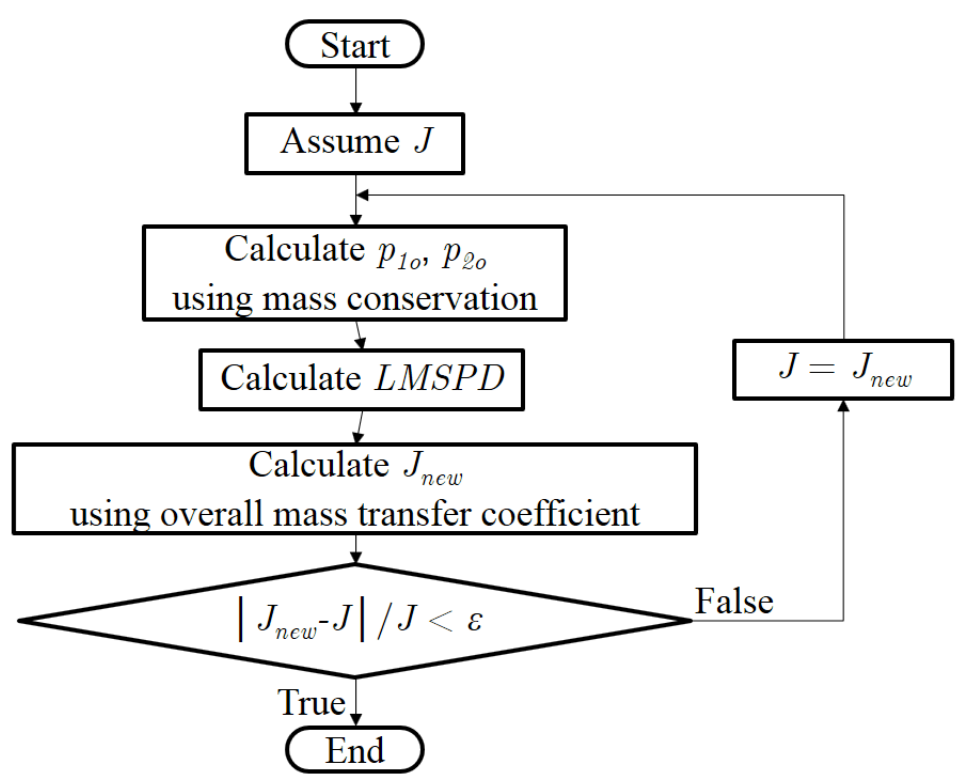


Figure 3 Iteration loop for the LMSPD code

A MATLAB code has been written based on the LMSPD method and the iteration loop shown above. The code calculates the mass transfer rate of a permeation window type bimolecular gas separation device made of metal at steady state. Required inputs include geometric dimensions of the device, flow rates of the solvent and the sweep gas, as well as transport coefficients of the gas to be separated in the materials. In this paper, it is referred to as the LMSPD code.

\section{BENCHMARK OF THE LMSPD CODE}

\section{1. $\mathrm{H}_{2}$ Permeation Experiment}

For the benchmark of the developed LMSPD code, comparisons to existing experimental data have been made. The ideal experiment would be tritium permeating through metal tubes or pipes in the cross-flow configuration. However, it appears that in the available literature, there are limited experiments of hydrogen isotopes permeating through metal tubes or pipes under flow conditions. Data concerning separation of hydrogen isotopes using a cross-flow permeation facility are rare. Among the experiments that are available, the experiment performed by Wang et al. has the operating conditions to which the LMSPD code can be applied (Wang et al., 2016). In the experiment, the $\mathrm{H}_{2}$ permeation flux through a hollow fiber made of $\mathrm{Ni}$ was measured under a variety of temperatures from 400 to $1000^{\circ} \mathrm{C}$. This experiment is used for the LMSPD code benchmark.

A model of $\mathrm{H}_{2}$ permeating through a Ni tube has been built and analyzed. The feed gas, which was a mixture of $\mathrm{H}_{2}$ with the carrier gas, flowed on the shell side, while the purging gas $\mathrm{N}_{2}$ flowed on the tube side of the Ni fiber in the co-current direction with $\mathrm{H}_{2} . \mathrm{H}_{2}$ concentration on the shell side was controlled by adjusting the ratio of $\mathrm{H}_{2}$ in the feed gas. As Ni possesses high hydrogen 
permeability, $\mathrm{H}_{2}$ diffused from the shell side, permeated through the wall, and entered the tube side. Outlet gases were analyzed using a gas chromatograph to determine the partial pressure difference between the two sides.

A schematic diagram of the experiment is shown in Figure 4. The inner and outer diameters of the permeation tube are 1.3 and $2.00 \mathrm{~mm}$, respectively. The effective length of the permeation section is $80 \mathrm{~mm}$. The flow rates of the gases on both sides are $0.5 \mathrm{ml} / \mathrm{s}$. The mass flow rates and velocities of both gases will vary with different experimental temperatures. For modeling purposes, the permeability value of $\mathrm{H}_{2}$ through Ni from Wang's experiments is used (Wang et al., 2016). In the experiments, the permeation rates of $\mathrm{H}_{2}$ through nickel hollow fiber membranes were measured under different temperatures. The permeances were then fitted to an Arrhenius plot against temperature to obtain the activation energy. The final obtained permeability of $\mathrm{H}_{2}$ in $\mathrm{Ni}$ is:

$$
P_{H, N i}=1.44 \times 10^{-6} \exp \left(-\frac{5.107 \times 10^{4}}{R T}\right)\left[\mathrm{mol} / \mathrm{m}-\mathrm{s}-\mathrm{Pa}^{0.5}\right]
$$

Hydrogen diffusion in gases is also considered in the model. In the experiments, three feed gases were tested: $50 \% \mathrm{H}_{2}-\mathrm{He}, 50 \% \mathrm{H}_{2}-\mathrm{CO}_{2}$ and $50 \% \mathrm{H}_{2}-2.5 \% \mathrm{CO}-\mathrm{N}_{2}$. The influence of carrier gas does not have a significant impact on the permeation of $\mathrm{H}_{2}$ through $\mathrm{Ni}$. In the model $50 \% \mathrm{H}_{2}-\mathrm{CO}_{2}$ is used as the feed gas. The transport coefficients, i.e., diffusivity and solubility, of $\mathrm{H}_{2}$ in $\mathrm{CO}_{2}$ and $\mathrm{N}_{2}$ are summarized in Table 3. Assuming all gases are ideal gases, the solubility of $\mathrm{H}_{2}$ in another gas can be estimated using the ideal gas law. 


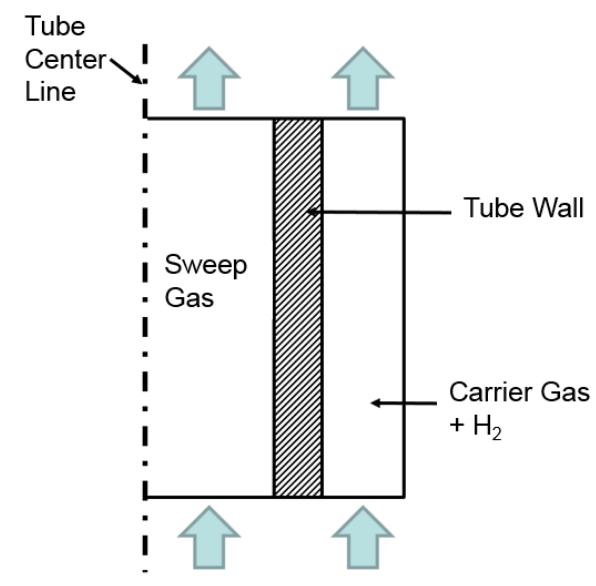

Figure 4 Schematic of co-current flow model

Table 3 Transport coefficients of $\mathrm{H}_{2}$ in $\mathrm{CO}_{2}$ and $\mathrm{N}_{2}$

\begin{tabular}{|c|c|c|}
\hline & $\begin{array}{c}\text { Diffusivity }\left[\text { atm- }{ }^{2} / \mathrm{s}\right](T \text { in }[\mathrm{K}]) \\
\text { (Marrero and Mason, 1972) }\end{array}$ & Solubility [mol $\left./ \mathrm{m}^{3}-\mathrm{Pa}\right]$ \\
\hline $\mathrm{CO}_{2}$ & $D_{\mathrm{CO}_{2}, \mathrm{H}}=\frac{3.14 \times 10^{-9} T^{1.750}}{\exp \left(\frac{11.7}{T}\right)}$ & $S_{\mathrm{CO}_{2}, \mathrm{H}}=\frac{n}{p V}=\frac{1}{R T}$ \\
\hline $\mathrm{N}_{2}$ & $D_{\mathrm{N}_{2}, \mathrm{H}}=\frac{1.539 \times 10^{-6} T^{1.548}}{\left[\ln \left(\frac{T}{3.16 \times 10^{-7}}\right)\right]^{2} \exp \left(-\frac{2.8}{T}\right) \exp \left(\frac{1067}{T^{2}}\right)}$ & $S_{\mathrm{N}_{2}, \mathrm{H}}=\frac{n}{p V}=\frac{1}{R T}$ \\
\hline
\end{tabular}

\subsection{Code Calculation Results}

The experimental data from Wang's paper for this study is shown in Figure 5 and Figure 6 by scattered points (Wang et al., 2016). In this plot, the partial pressures used in the x-axis are calculated from the concentration measurements at the gas outlets. 


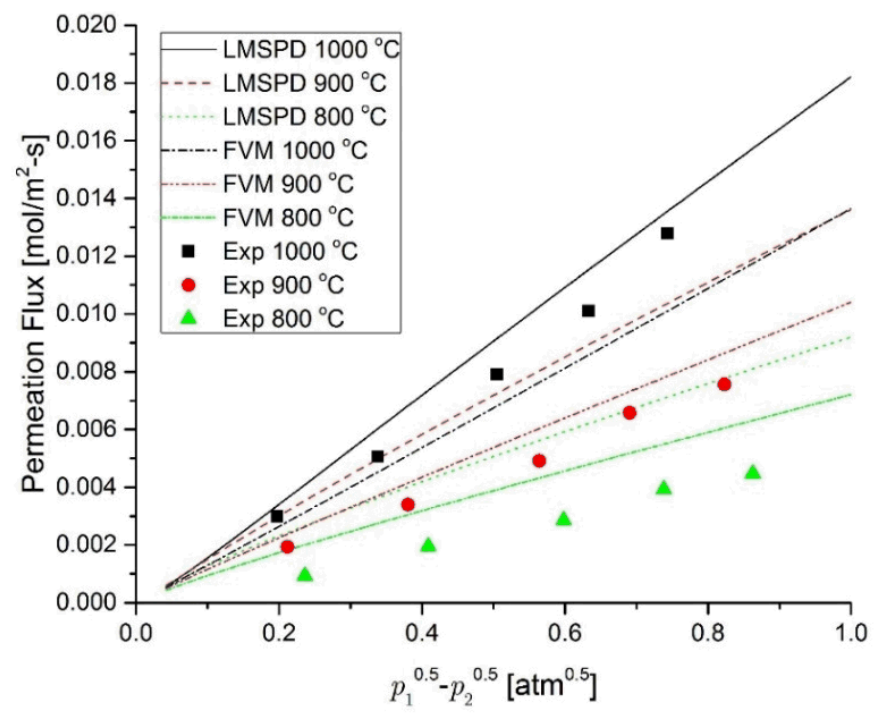

Figure 5 Comparison of code calculation results and experimental data $\left(800-1000^{\circ} \mathrm{C}\right)$

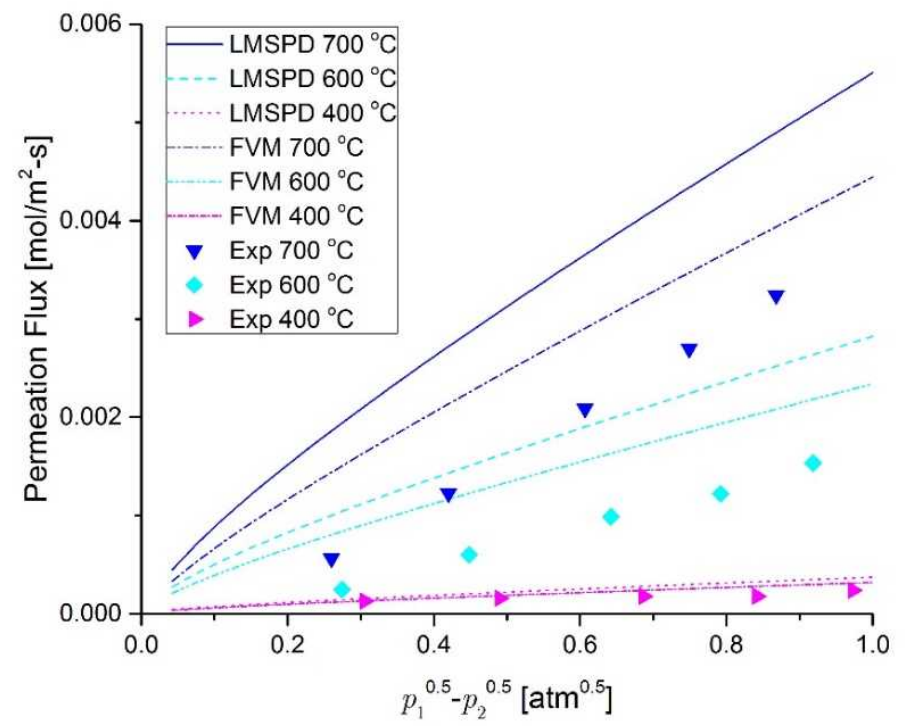

Figure 6 Comparison of code calculation results and experimental data $\left(400-700^{\circ} \mathrm{C}\right)$

For the convenience of benchmark, the code calculation results are also expressed in the permeation flux. The original experiment was performed under a variety of temperatures. To 
examine how temperature influences the code calculation, the temperatures used in the calculation are set to be the same with the experimental temperatures, i.e., $400^{\circ} \mathrm{C}, 600^{\circ} \mathrm{C}, 700^{\circ} \mathrm{C}, 800^{\circ} \mathrm{C}$, $900^{\circ} \mathrm{C}$ and $1000^{\circ} \mathrm{C}$. The entire geometry is assumed to be at the same temperature in each case. The range of the partial pressure difference is slightly larger in the code calculation to fully cover the range performed in the original experiment.

The calculated $\mathrm{H}_{2}$ permeation flux under different temperatures is plotted against the difference of square root of the partial pressures in Figure 5 and Figure 6. With the increase of the partial pressure difference, the tritium permeation flux increases. The gas temperature also affects the permeation flux by influencing the mass transport coefficients. At the same partial pressure difference, the higher the temperature is, the larger the permeation flux becomes.

The same model was also calculated by a MATLAB code written based on a coupled heat transfer and tritium mass transport model (Zhang et al., 2017), where the geometry was divided into segments and in each segment local mass and energy balances were imposed. This coupled code is referred to as the "Finite Volume Method code" (FVM code) in this paper. In the FVM code, tritium permeation is one dimensional from the tube wall outer surface (shell side) to the inner surface (tube side). It is assumed that the hydrogen concentration profiles in both the carrier gas and sweep gas are flat. In other words, the gradient of $\mathrm{H}_{2}$ partial pressure exits only in the tube wall. The tube wall is divided into segments only in the axial direction but not in the radial direction. The results of the FVM code are also plotted in Figure 5 and Figure 6. Same to the results obtained from the LMSPD code and in consistence with expected from theoretical basis, the 
hydrogen permeation flux increases with the increase of temperature or hydrogen partial pressure difference.

From the results it can be observed that temperature has a significant effect on the permeation flux. As an example for high temperatures, the permeation flux at $1000^{\circ} \mathrm{C}$ obtained from the two codes are compared with the experimental data. In general, the LMSPD code overestimates the permeation flux while the FVM code underestimates it. The average difference between the LMSPD code results and experimental data is $13.3 \%$. The average difference between FVM code results and experimental data is $14.7 \%$.

As the temperature decreases, the absolute differences between both code results and the experimental data are of the same magnitudes, while the relative differences become larger because the values of the permeation flux also decrease. For even lower temperatures, for instance, at $600^{\circ} \mathrm{C}$, both codes tend to overestimate the permeation flux. The differences between the calculation results and the experimental data at $600^{\circ} \mathrm{C}$ are apparently larger than those at $1000^{\circ} \mathrm{C}$. For lower difference values of the square root of the partial pressure, the code calculation results could be as high as two or three times greater than the experimental results. At $400^{\circ} \mathrm{C}$, the differences between code results and the experimental data are smaller than those at $600^{\circ} \mathrm{C}$, while still about four times larger than those at $1000^{\circ} \mathrm{C}$.

The normal operation temperature of FHRs is about $700^{\circ} \mathrm{C}$. The tritium permeation rate at $700^{\circ} \mathrm{C}$ is of particular interest in this study. Therefore, the calculation results and the experimental data at $700^{\circ} \mathrm{C}$ are compared. The calculated permeation flux from both codes are higher than the experimental data by $6.97 \times 10^{-4}-1.66 \times 10^{-3} \mathrm{~mol} / \mathrm{m}^{2}$-s. Comparing the results obtained from the two codes, the hydrogen permeation flux calculated from the LMSPD code is higher than that calculated from the FVM code by $4.21 \times 10^{-4}-9.59 \times 10^{-4} \mathrm{~mol} / \mathrm{m}^{2}-\mathrm{s}$. 


\subsection{Discussion of Results}

\subsubsection{Difference between code calculation and experimental data}

The absolute and relative differences between the code calculations and experimental data are shown in Table 4. The differences are larger at lower temperatures and with smaller driving forces, i.e., smaller values in the difference of square roots of partial pressures on two sides. Comparing the absolute difference between the code calculation results and the experimental data, it can be found that the value always falls in the $10^{-6}-10^{-3}$ magnitude range. The relative difference, however, becomes significant when the permeation flux is low.

Table 4 Difference of permeation flux between the code results and experimental data

\begin{tabular}{|c|c|c|c|c|c|c|}
\hline $\begin{array}{c}\text { Temperature } \\
{\left[{ }^{\circ} \mathrm{C}\right]}\end{array}$ & Code & Type & $\begin{array}{c}\text { Min. } \\
\text { difference }\end{array}$ & $\begin{array}{c}p_{1}^{0.5}-p_{2}{ }^{0.5} \\
{\left[\mathrm{~atm}^{0.5}\right]}\end{array}$ & $\begin{array}{c}\text { Max. } \\
\text { difference }\end{array}$ & $\begin{array}{c}p_{1}^{0.5}-p_{2}^{0.5} \\
{\left[\mathrm{~atm}^{0.5}\right]}\end{array}$ \\
\hline \multirow[t]{4}{*}{1000} & \multirow[t]{2}{*}{ LMSPD } & Absolute & $3.58 \times 10^{-4}$ & 0.20 & $1.43 \times 10^{-3}$ & 0.63 \\
\hline & & Relative (\%) & 5.91 & 0.74 & 19.0 & 0.34 \\
\hline & \multirow[t]{2}{*}{ FVM } & Absolute & $3.92 \times 10^{-4}$ & 0.20 & $2.69 \times 10^{-3}$ & 0.74 \\
\hline & & Relative (\%) & 10.6 & 0.34 & 21.1 & 0.74 \\
\hline \multirow[t]{4}{*}{900} & \multirow[t]{2}{*}{ LMSPD } & Absolute & $1.27 \times 10^{-3}$ & 0.21 & $3.88 \times 10^{-3}$ & 0.82 \\
\hline & & Relative (\%) & 47.9 & 0.69 & 65.9 & 0.21 \\
\hline & \multirow[t]{2}{*}{$\overline{F V M}$} & Absolute & $4.57 \times 10^{-4}$ & 0.21 & $1.16 \times 10^{-3}$ & 0.56 \\
\hline & & Relative (\%) & 11.7 & 0.69 & 24.0 & 0.56 \\
\hline \multirow[t]{4}{*}{800} & \multirow[t]{2}{*}{ LMSPD } & Absolute & $1.73 \times 10^{-3}$ & 0.24 & $3.62 \times 10^{-3}$ & 0.86 \\
\hline & & Relative (\%) & 80.0 & 0.74 & 184 & 0.24 \\
\hline & \multirow[t]{2}{*}{ FVM } & Absolute & $1.06 \times 10^{-3}$ & 0.24 & $1.83 \times 10^{-3}$ & 0.86 \\
\hline & & Relative (\%) & 39.6 & 0.74 & 113 & 0.24 \\
\hline
\end{tabular}




\begin{tabular}{|c|c|c|c|c|c|c|}
\hline \multirow[t]{4}{*}{700} & \multirow[t]{2}{*}{ LMSPD } & Absolute & $1.30 \times 10^{-3}$ & 0.26 & $1.66 \times 10^{-3}$ & 0.87 \\
\hline & & Relative (\%) & 51.1 & 0.87 & 230 & 0.26 \\
\hline & \multirow[t]{2}{*}{ FVM } & Absolute & $6.97 \times 10^{-4}$ & 0.87 & $9.06 \times 10^{-4}$ & 0.42 \\
\hline & & Relative (\%) & 21.5 & 0.87 & 155 & 0.26 \\
\hline \multirow[t]{4}{*}{600} & \multirow[t]{2}{*}{ LMSPD } & Absolute & $7.94 \times 10^{-4}$ & 0.27 & $1.12 \times 10^{-3}$ & 0.79 \\
\hline & & Relative (\%) & 72.0 & 0.92 & 318 & 0.27 \\
\hline & \multirow[t]{2}{*}{ FVM } & Absolute & $5.90 \times 10^{-4}$ & 0.27 & $7.13 \times 10^{-4}$ & 0.79 \\
\hline & & Relative (\%) & 42.3 & 0.92 & 236 & 0.27 \\
\hline \multirow[t]{4}{*}{400} & \multirow[t]{2}{*}{ LMSPD } & Absolute & $2.43 \times 10^{-5}$ & 0.31 & $1.47 \times 10^{-4}$ & 0.84 \\
\hline & & Relative (\%) & 18.5 & 0.31 & 81.6 & 0.84 \\
\hline & \multirow[t]{2}{*}{ FVM } & Absolute & $1.18 \times 10^{-6}$ & 0.31 & $1.00 \times 10^{-4}$ & 0.84 \\
\hline & & Relative (\%) & 0.90 & 0.31 & 55.7 & 0.84 \\
\hline
\end{tabular}

There are several potential reasons for the differences between code calculation results and the experimental data. Temperature is a main factor affecting the permeation flux. Compared to higher temperatures, at lower temperatures, the permeability of hydrogen through a nickel wall decreases, and therefore, the amount of hydrogen permeating through the wall is less than that at higher temperatures. The absolute differences between code results and the experimental data are reasonable, and are of the same magnitude with the differences at higher temperatures. However, since the permeation rates are much smaller at lower temperatures, the relative differences appear much larger than those at higher temperatures. The larger differences at smaller driving forces can also be explained by the decreased hydrogen permeation rates. For application in FHRs, the temperature range of most interested is the operating temperature of the tritium removal facility, i.e., above $700^{\circ} \mathrm{C}$, at which temperatures the agreement between the codes and the experimental data is good. In the sections where the operating temperature is lower, tritium leakage from the 
primary coolant to the surrounding environment is relatively small. Therefore, even a larger relative uncertainty of the code prediction might not be of a considerable concern.

Surface conditions of the permeation tube also have an effect on the hydrogen permeation flux. In the experiments, the nickel tube surface could be oxidized, which decreases the permeation flux. Surface oxidation could be a possible cause of the overestimation of both codes at most of the temperatures modeled. In addition, although the information of measurement uncertainties is not available for the original experiments, from the principles of gas chromatographic method, measurement uncertainties have a more dominant effect when the concentration is low (Harvey, 2000).

\subsubsection{Permeation flux and the difference of the square root of the partial pressure}

The mass transfer coefficients of $\mathrm{H}_{2}$ in all three domains are compared in Table 5. The mass transfer coefficient in the tube wall is several orders of magnitude lower than that in the sweep gas or the feed gas, showing that the main resistance exists in the tube wall. Due to this difference, omitting the mass transfer resistance in gases would not have a significant effect on the calculation results. Therefore, only hydrogen permeation through the wall is considered in the FVM code.

Table 5 Comparison of the mass transport coefficients in different domains

\begin{tabular}{|c|l|l|l|l|}
\hline Temperature & $p_{1}{ }^{0.5}-p_{2}{ }^{0.5}$ \\
{$\left[{ }^{\circ} \mathrm{C}\right]$} & {$\left[\mathrm{atm}^{0.5}\right]$} & \multicolumn{3}{|l|}{ Mass transfer coefficient $\left[\mathrm{mol} / \mathrm{m}^{2}\right.$-s-Pa $]$} \\
\cline { 3 - 5 } & 0.125 & $5.80 \times 10^{-3}$ & $8.53 \times 10^{-8}$ & \multicolumn{1}{|c|}{ Sweep gas } \\
\hline 1000 & $0.27 \times 10^{-4}$ \\
\cline { 2 - 5 } & 0.743 & $6.00 \times 10^{-3}$ & $8.07 \times 10^{-8}$ & $2.40 \times 10^{-4}$ \\
\hline \multirow{2}{*}{900} & 0.212 & $2.51 \times 10^{-3}$ & $1.96 \times 10^{-7}$ & $6.85 \times 10^{-5}$ \\
\cline { 2 - 5 } & 0.823 & $6.88 \times 10^{-3}$ & $4.65 \times 10^{-8}$ & $2.89 \times 10^{-4}$ \\
\hline 800 & 0.236 & $2.79 \times 10^{-3}$ & $1.08 \times 10^{-7}$ & $8.00 \times 10^{-5}$ \\
\cline { 2 - 5 } & 0.862 & $7.52 \times 10^{-3}$ & $2.65 \times 10^{-8}$ & $3.26 \times 10^{-4}$ \\
\hline
\end{tabular}




\begin{tabular}{|l|l|l|l|l|}
\hline 700 & 0.260 & $3.17 \times 10^{-3}$ & $5.33 \times 10^{-8}$ & $9.51 \times 10^{-5}$ \\
\cline { 2 - 5 } & 0.868 & $7.94 \times 10^{-3}$ & $1.44 \times 10^{-8}$ & $3.52 \times 10^{-4}$ \\
\hline \multirow{3}{*}{600} & 0.274 & $3.60 \times 10^{-3}$ & $2.32 \times 10^{-8}$ & $1.12 \times 10^{-4}$ \\
\cline { 2 - 5 } & 0.918 & $8.67 \times 10^{-3}$ & $6.54 \times 10^{-9}$ & $3.99 \times 10^{-4}$ \\
\hline 400 & 0.306 & $4.50 \times 10^{-3}$ & $2.43 \times 10^{-9}$ & $1.53 \times 10^{-4}$ \\
\cline { 2 - 5 } & 0.973 & $9.94 \times 10^{-3}$ & $7.58 \times 10^{-10}$ & $4.91 \times 10^{-4}$ \\
\hline
\end{tabular}

The permeation flux is directly related to the difference of square roots of partial pressures on both sides. The linearity of the curves of permeation flux calculated from LMSPD and FVM codes shown in Figure 5 and Figure 6 are apparent and consistent with the form of Eq. (16). Fitting the

code results in Figure 5-Figure 6 to linear relationships with $\left(\sqrt{p_{1}}-\sqrt{p_{2}}\right)$, the $\mathrm{R}^{2}$ values of the fitted correlations are above 0.94. This is consistent with what is predicted in the Sievert's equation (Lee et al., 2013), confirming that the assumption of diffusion in the wall being a rate-dominating step is reasonable.

\section{CALCULATION OF THE CROSS-FLOW TRITIUM REMOVAL FACILITY}

For each of the two sets of dimensions listed in Table 1, a calculation has been performed using the LMSPD mass transfer code. The geometry used in the calculations is a single tube. The tritium removal rate can be scaled up for a full assembly with adjustment for tube numbers. Effects of the fluid flow rates and inlet $T_{2}$ concentration on the performance of the cross-flow tritium removal facility have been investigated. The inlet $T_{2}$ concentration is fixed at $1.8 \times 10^{-6} \mathrm{~mol} / \mathrm{m}^{3}$ when the flow rates are varied. The molten salt or purging gas flow rate is fixed at $1 \mathrm{~m} / \mathrm{s}$ when other parameters are varying. In Figure 7, the tritium removal percentage is plotted against the molten salt flow velocity while in Figure 8 , it is plotted against the sweep gas flow velocity. The inlet $T_{2}$ concentration on the molten salt side also effects the performance of the facility, as plotted in 
Figure 9. The tritium removal percentage is evaluated using the initial tritium concentration in the primary coolant, i.e., $1.8 \times 10^{-6} \mathrm{~mol} / \mathrm{m}^{3}$.

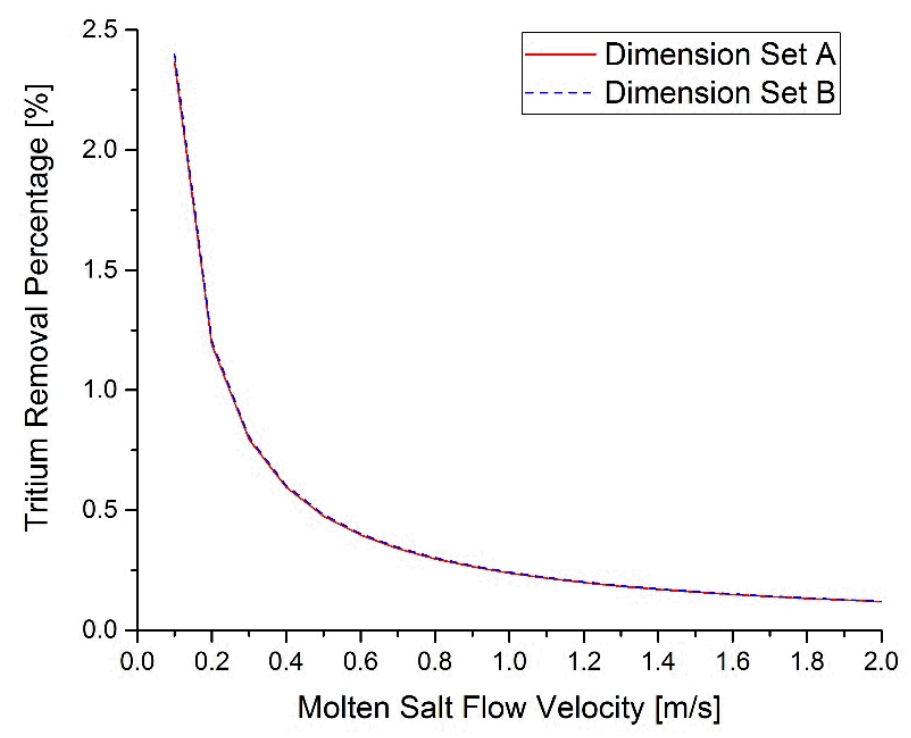

Figure 7 Effect of the molten salt flow velocity on tritium removal performance

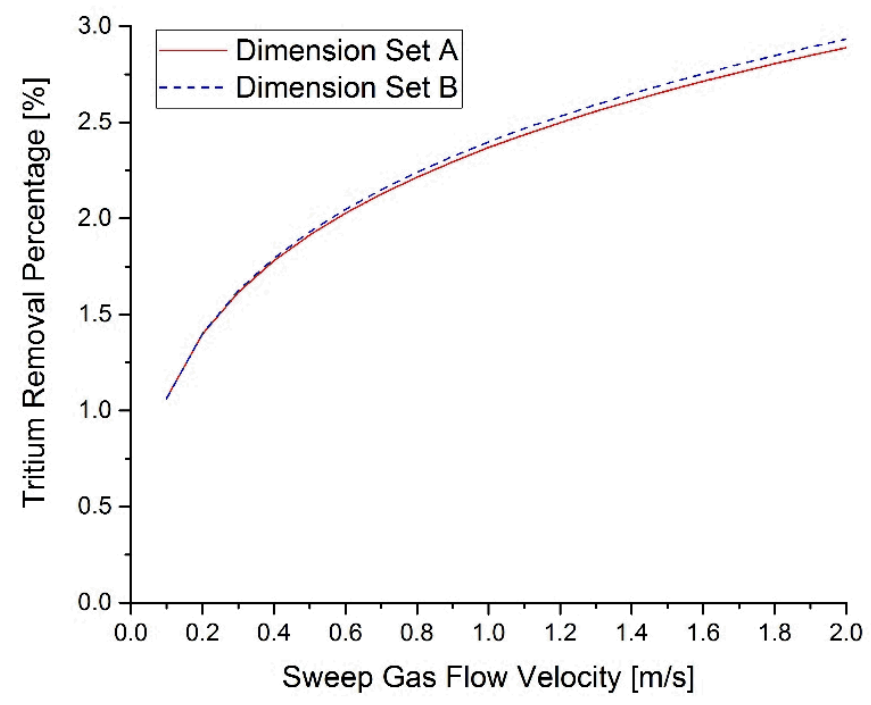

Figure 8 Effect of the sweep gas flow velocity on tritium removal performance 


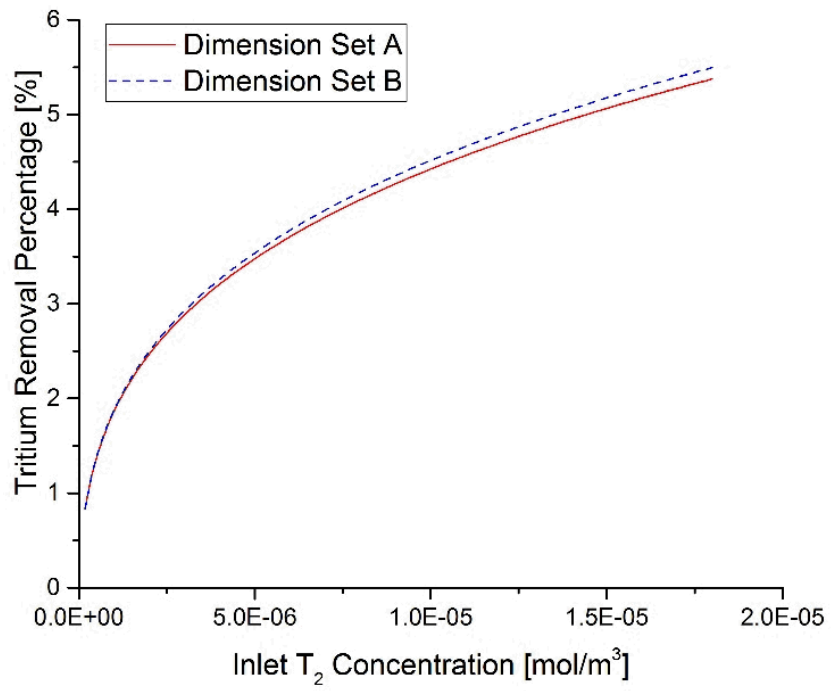

Figure 9 Effect of the molten salt inlet $\mathrm{T}_{2}$ concentration on tritium removal performance

The results show that the performance of the cross-flow tritium removal facility can be affected by both the fluid flow rates and inlet $T_{2}$ concentration. The tritium removal rate increases with the decrease of the molten salt flow rate. This is because the longer the molten salt stays in the removal facility, the more tritium will be carried away by the sweep gas. Increasing the flow rate of the sweep gas can also accelerate the tritium removal rate since it reduces the average $\mathrm{T}_{2}$ concentration on the sweep gas side, increasing the driving force. Raising the inlet $\mathrm{T}_{2}$ concentration in the molten salt is a direct way to increase the driving force, and achieve a higher tritium removal rate. In actual applications, to achieve a higher $\mathrm{T}_{2}$ inlet concentration on the molten salt side means that the $\mathrm{T}_{2}$ concentration in the entire primary loop is increased. However, a higher $\mathrm{T}_{2}$ concentration in the primary loop could lead to a higher probability of $\mathrm{T}_{2}$ release to other parts of the loop. Mitigating measures, such as tritium permeation reduction coatings, must be adopted to reduce tritium leakage through other structural materials in the primary loop. Therefore, a compromise must be made regarding the $\mathrm{T}_{2}$ concentration in the primary coolant. 
The effects of flow rates and the inlet $T_{2}$ concentration on the $T_{2}$ removal rate can be applied to fine adjustment of meeting a specific tritium removal rate requirement. However, changing the inlet $T_{2}$ concentration requires time for the system to reach the new equilibrium, and changing flow rates requires reevaluation of the permeation rate, for quick adjustment of the tritium removal rate, the modular design of the tritium removal facility is of advantages. Via adjusting the modules in operation, the tritium removal rate can be coarsely adjusted within a timely manner.

\section{CONCLUSIONS}

Tritium generated in the primary coolant FLiBe in FHRs needs to be effectively managed and controlled. In this study, a cross-flow tritium removal facility is studied and the logarithmic mean difference of the square root of the partial pressures is used to calculate the overall mass transfer coefficient of the facility. A code has been developed based on the LMSPD method and can be used for bimolecular gas permeating through metal tube walls or membranes. Comparison of the code results to available experimental data showed good consistency, with absolute differences in the permeation flux to be below $10^{-3} \mathrm{~mol} / \mathrm{m}^{2}$-s. The LMSPD code was also compared with another computer code using the segmentation method, i.e., the FVM code, and the comparison showed reasonably good agreement at the temperatures of interest for FHR operation.

The LMSPD code was then used to evaluate the effectiveness of the proposed cross-flow tritium removal facility. Calculation results showed that the performance of the facility would be affected by the molten salt flow velocity, sweep gas flow velocity, and tritium inlet concentration in the primary coolant. Based on this evaluation the proposed design of the facility and its operation conditions can be improved.

In actual applications, the Sievert's law may not be always valid due to surface conditions being not ideal, complex alloy structures, etc. The power of the partial pressure in the law might 
vary between 0.5 and 1 . A laboratory-scale cross-flow test facility is planned to be tested for the removal efficiency of hydrogen isotopes. The acquired experimental data will be used to validate the mass transport analysis code using LMSPD and potentially improve the model for more general applications.

\section{ACKNOWLEDGEMENTS}

This research is being performed using funding received from the DOE Office of Nuclear Energy's Nuclear Energy University Program (NEUP). The authors appreciate the financial support from the DOE NEUP office.

The authors would like to acknowledge Dr. David Holcomb of the Oak Ridge National Laboratory for his insightful advice and valuable suggestions to this work. 


\section{NOMENCLATURE}

Variables

A mass transfer area, $\left[\mathrm{m}^{2}\right]$

$c \quad$ concentration of gas

$c_{p} \quad$ heat capacity, $[\mathrm{J} / \mathrm{kg}-\mathrm{K}]$

$D \quad$ diffusivity of the gas, $\left[\mathrm{m}^{2} / \mathrm{s}\right]$

$D_{H} \quad$ diffusivity of $\mathrm{H}_{2},\left[\mathrm{~m}^{2} / \mathrm{s}\right]$

$d \quad$ tube diameter, [m]

$d_{h} \quad$ hydraulic diameter, [m]

$h \quad$ mass transfer coefficient based on concentration of the gas, $\left[\mathrm{mol} / \mathrm{m}^{2}-\mathrm{s}-\mathrm{Pa}{ }^{0.5}\right]$

$h_{p} \quad$ mass transfer coefficient based on partial pressure of the gas, $\left[\mathrm{mol} / \mathrm{m}^{2}-\mathrm{s}-\mathrm{Pa}\right]$

ho overall mass transfer coefficient, $\left[\mathrm{mol} / \mathrm{m}^{2}-\mathrm{s}-\mathrm{Pa}\right]$

$h_{t} \quad$ heat transfer coefficient, $\left[\mathrm{W} / \mathrm{m}^{2}-\mathrm{K}\right]$

$J \quad$ permeation flux, $\left[\mathrm{mol} / \mathrm{m}^{2}-\mathrm{s}\right]$

$K \quad$ Sievert's constant of gas, $\left[\mathrm{mol} / \mathrm{m}^{3}-\mathrm{Pa}^{0.5}\right]$

$k \quad$ thermal conductivity, $[\mathrm{W} / \mathrm{m}-\mathrm{K}]$

$k_{w} \quad$ mass transfer conductivity of gas in the metal tube wall, [mol/m-s-Pa]

$L \quad$ tube length, $[\mathrm{m}]$

LMSPD logarithmic mean difference of square roots of partial pressures of permeating gas between the primary and secondary bulk fluid, $\left[\mathrm{Pa}^{0.5}\right]$

l characteristic length, [m]

$n \quad$ amount of gas, [mol]

$P_{w} \quad$ permeability of gas in the wall, $\left[\mathrm{mol} / \mathrm{m}-\mathrm{s}-\mathrm{Pa}^{0.5}\right]$ 


$\begin{array}{ll}p & \text { partial pressure of gas, }[\mathrm{Pa}] \\ R & \text { ideal gas constant, }[\mathrm{J} / \mathrm{mol}-\mathrm{K}] \\ S_{H} & \text { solubility of } \mathrm{H}_{2},\left[\mathrm{~mol} / \mathrm{m}^{3}\right] \\ T & \text { temperature, }\left[{ }^{\circ} \mathrm{C}\right] \text { or }[\mathrm{K}] \\ V & \text { molar volume of gas, }\left[\mathrm{m}^{3} / \mathrm{mol}\right]\end{array}$

Greeks

$\begin{array}{ll}\alpha & \text { thermal diffusivity, }\left[\mathrm{m}^{2} / \mathrm{s}\right] \\ \beta & \text { thermal expansion coefficient, }[1 / \mathrm{K}] \\ \sigma & \text { cross section, [barn] } \\ \delta & \text { wall thickness [m] } \\ \mu & \text { dynamic viscosity, }\left[\mathrm{N}-\mathrm{s} / \mathrm{m}^{2}\right] \\ v & \text { momentum viscosity, }\left[\mathrm{m}^{2} / \mathrm{s}\right] \\ \rho & \text { density, }\left[\mathrm{kg} / \mathrm{m}^{3}\right]\end{array}$

Non-dimensional numbers

Gr Grashof number

$\mathrm{Nu} \quad$ Nusselt number

Pe Peclet number

Pr Prantdl number

Sc Schmidt number

Sh Sherwood number

St Stanton number 


$\begin{array}{ll}\text { Subscripts } & \\ 1 & \text { primary side } \\ \text { avg } & \text { secondary side } \\ b & \text { average value } \\ w & \text { bulk fluid } \\ \mathrm{N}_{2} & \text { in nitrogen } \\ \mathrm{CO}_{2} & \text { in carbon dioxide } \\ i & \text { at the flow inlet } \\ o & \text { at the flow outlet } \\ t h & \text { thermal neutron properties }\end{array}$

\section{REFERENCES}

Ackerman, F. J., Koskinas, G.J., 1972. Permeation of hydrogen and deuterium through palladiumsilver alloys. Journal of Chemical and Engineering Data 17 (1), 51-55.

Andrew, P.L., Haasz, A.A, 1992. Models for hydrogen permeation in metals. Journal of Applied Physics 72 (7), 2749-2757.

Deveau, N. D., Ma, Y.H., Datta. R., 2013. Beyond Sieverts' law: a comprehensive microkinetic model of hydrogen permeation in dense metal membranes. Journal of Membrane Science 437, 298-311.

Gorman, J.K., Nardella. W.R., 1962. Hydrogen permeation through metals. Vacuum 12 (1), 1924.

Harvey, D., 2000. Modern analytical chemistry. New York: McGraw-Hill. 
Ingersoll, D.T., Forsberg, C.W., Ott, L.J., Williams, D.F., Renier, J.P., Wilson, D.F., Ball, S.J., Reid, L., Corwin, W.R., Del Cul, G.D., Peterson, P.F., Zhao, H., Pickard, P.S., Parma, E.J., Vernon, M., 2004. Status of preconceptual design of the advanced high-temperature reactor (AHTR). Oak Ridge National Laboratory, ORNL/TM-2004/104.

Lee, S. K., Ohn, Y.G., Noh. S.J., 2013. Measurement of hydrogen permeation through nickel in the elevated temperature range of $450-850^{\circ}$ C. Journal of the Korean Physical Society 10 (63), 1955-1961.

Locatelli, G., Mancini, M., Todeschini, N., 2013. Generation IV nuclear reactors: Current status and future prospects. Energy Policy 61, 1503-1520.

Marrero, T.R., Mason, E.A., 1972. Gaseous diffusion coefficient. Journal of Physics Chemistry Reference Data 1(1).

Nelson, H.G., Stein, J.E., 1973. Gas-phase hydrogen permeation through alpha iron, 4130 steel, and 304 stainless steel from less than $100 \mathrm{C}$ to near $600 \mathrm{C}$.

US Nuclear Regulatory Commission, 2004. TRISO-coated particle fuel phenomenon identification and ranking tables (PIRTs) for fission product transport due to manufacturing, operations, and accidents. NUREG/CR-6844 (1).

Forsberg, C.W., Hu, L., Peterson, P.F., Sridharan, K., 2014. Fluoride-salt-cooled Hightemperature Reactor (FHR) for power and process heat final project report. MIT-ANP-TR157, Center for Advanced Nuclear Energy Systems, Massachusetts Institute of Technology.

Forsberg, C.W., Lam, S., Carpenter, D.M., Whyte, D.G., Scarlat, R., Contescu, C., Wei, L., Stempien, J. and Blandford, E., 2017. Tritium control and capture in salt-cooled fission and fusion reactors: status, challenges, and path forward. Nuclear Technology. 197, 119-139.

Fisher, D.J., 1999. Hydrogen diffusion in metals: a 30-year retrospective. Trans Tech Publication. 
Fukada, S., Mitsuishi, N., 1988a. Hydrogen permeation through walls with laminar-flow between two parallel plate walls. Journal of Nuclear Science and Technology. 25 (5), 479-488.

Fukada, S., Mitsuishi, N., 1988b. Effects of mass transfer resistances in fluid and permeable walls on hydrogen permeation in tube-type metal window. Journal of Nuclear Science and Technology 25 (7), 600-603.

Olson, L.C., Ambrosek, J.W., Sridharan, K., Anderson, M.H. and Allen, T.R., 2009. Materials corrosion in molten LiF-NaF-KF salt. Journal of Fluorine Chemistry 130 (1), 67-73.

Qin, H,. Wang, C., Qiu, S., Zhang, D., Tian, W. and Su, G. H., 2018. Study of tritium transport characteristics in a transportable fluoride-salt-cooled high-temperature reactor. International Journal of Energy Research 42 (4), 1536-1550.

Ranz, W.E. and Marshall, W.R., 1952. Evaporation from drops. Chem. Eng. Prog. 48 (3), 141146.

Sinha, A.P., De, P., 2012. Mass transfer: principles and operations. PHI Learning Pvt. Ltd.

Stempien, J.D., 2015. Tritium transport, corrosion, and fuel performance modeling in the Fluoride Salt-Cooled High-Temperature Reactor (FHR). PhD diss., Massachusetts Institute of Technology.

Steward, S.A, 1983. Review of hydrogen isotope permeability through materials. No. UCRL53441. Lawrence Livermore National Laboratory.

Treybal, R.E., 1980. Mass-Transfer Operations, New York: McGraw-Hill.

University of Toronto, Institute for Aerospace Studies, 1991. Hydrogen permeation through bilayer metallic membranes.

Wang, M., Song, J., Li, Y., Tan, X., Chu, Y., Liu, S., 2017. Hydrogen separation at elevated temperatures using metallic nickel hollow fiber membranes. AIChE Journal 63 (7), 3026-3034. 
Watson, J.S., 1972. Evaluation of methods for recovering tritium from the blankets or coolant systems of fusion reactors. No. ORNL-TM-3794.

Wu, X., 2016. Design of a Tritium Mitigation and Control System for Fluoride-salt-cooled Hightemperature Reactor Systems. MS Thesis, The Ohio State University, Department of Mechanical and Aerospace Engineering.

Wu, X., Zhang, S., Shi, S., Sun, X., Holcomb, D., Christensen, R., Sabharwall, P., 2016. Tritium release limit for fluoride-salt-cooled high-temperature reactors," Transactions of the American Nuclear Society, 115, Las Vegas, NV, November 6-10, 2016.

Wang, M., Song, J., Wu, X., Tan, X., Meng, B., Liu, S., 2016. Metallic nickel hollow fiber membranes for hydrogen separation at high temperatures. Journal of Membrane Science, 509, 156-163.

Zhang, S., Shi, S., Wu, X., Sun, X., Christensen, R., 2017. Double-Wall Natural Draft Heat Exchanger Design for Tritium Control in FHRs. Proceedings of the 2017 25th International Conference on Nuclear Engineering ICONE25. May 14-18, Shanghai, China, 2017. 